\title{
A Systematic Review of Audiology Terminology
}

\author{
Soo Hee $\mathrm{Oh}^{1}$ and Junghak Lee ${ }^{2}$ \\ ${ }^{1}$ Audiology Institute, Hallym University of Graduate Studies, Seoul, \\ ${ }^{2}$ Department of Audiology, Hallym University of Graduate Studies, Seoul, Korea
}

$\begin{array}{ll}\text { Received } & \text { January 21, 2016 } \\ \text { Revised } & \text { February 2, 2016 } \\ \text { Accepted } & \text { February 13, 2016 }\end{array}$

Address for correspondence

Junghak Lee, FAAA, BCA, PhD

Department of Audiology,

Hallym University

of Graduate Studies,

427 Yeoksam-ro, Gangnam-gu,

Seoul 06198, Korea

Tel +82-2-2051-4950

Fax +82-2-3453-6618

E-mail leejh@hallym.ac.kr
The present report provides an overview of terminology studies in audiology including topics and study characteristics, as well as categorizing the main issues. The goals are to improve the understanding of the current issues for terminology in audiology and to provide some basic information that will be useful to develop an international standard. Search procedures were completed over two phases. Phase 1 included a systematic electronic searches using MEDLINE (PubMed), Excerpta Medica Database, Cumulative Index to Nursing and Allied Health Literature, and International Organization for Standardization with keywords related to terminology of audiology. The studies were initially identified according to the titles of 2921 publications following careful abstract examination. Of these, whole texts of 16 publications were retrieved. Five papers met the inclusion criteria were further investigated. In phase 2, a manual search was conducted to collect additional publications with keywords related to terminology project in audiology. A total of 16 papers were found. The essential terminology issues classified included 'appropriateness,' 'classification/framework,' 'inconsistency of terminology,' 'multilingual and international aspects,' and 'service quality/delivery including communication and accessibility.' This was indicative of the paucity of terminology research in audiology, despite recurring terminology issues. Establishment of standardized terminology in audiology may minimize current challenging terminology issues by improving appropriateness and consistency of terminology as well as communication among relevant stakeholders at national and international levels.

J Audiol Otol 2016;20(2):109-113

KEY WORDS: Audiology · Standardization · Terminology.

\section{Introduction}

Audiology is a field of study dealing with assessment, diagnoses, treatment, rehabilitation, and prevention of hearing and balance disorders [1,2]. It is generally accepted that one of the main purposes of audiology is to improve human communication by providing audiology services and establishing an effective multi-sector collaboration, as a major field of communication sciences and disorders (CSD) with speechlanguage pathology. In recent years, the global audiology market is increasing due to a rapid population growth of agerelated hearing loss [3]. The use of standardized and consis-

This is an Open Access article distributed under the terms of the Creative Commons Attribution Non-Commercial License (http://creativecommons. org/licenses/by-nc/3.0/) which permits unrestricted non-commercial use, distribution, and reproduction in any medium, provided the original work is properly cited. tent terms is integral in minimizing difficulties in comprehension and interpretation across stakeholders $[4,5]$. However, this uniformity of terminology is not always achieved in CSD. Although a number of CSD terminology projects have been conducted over the last 40 years [6], challenging issues still remain unresolved. Walsh [7] described several factors contributing to the inconsistent terminology in CSD, centering on speech-language-pathology. These include complexity of human communication, lack of models of disability, and multiple views among stakeholders. Relevant to the Walsh's study, the International Group on Terminology Framework for Communication Sciences and Disorders (IGOTF-CSD, 2006) [8] undertook to improve the "appropriateness, accessibility, and consistency" of terminology issues in CSD, considering both professional and public sectors [9]. The project mainly emphasized establishing an international collaboration, initiating professional awareness, identifying terminol- 
ogy related issues for documentation, and developing terminology frameworks in CSD [8].

Compared to most previous studies focusing on terminology issues in speech-language pathology of CSD, only a few recent reports [10-14] have discussed some terminology issues in audiology. Consistent and appropriate terminology in audiology is very important to develop professional disciplines because the use of inconsistent terms in audiology disrupts communication with other professionals, diagnostic evaluation, and documentation [10]. For these reasons, the establishment of standardized terms among professionals to improve communication represents an important challenge for audiologists and relevant professionals.

The present report provides an overview of terminology studies in audiology including topics and study characteristics, as well as categorizing the main issues. The goals are to improve the understanding of the current issues for audiology terminology and to provide some basic information that will be useful to develop an international standard.

\section{Materials and Methods}

Search procedures were completed over two phases. Phase 1 included a systematic electronic searches using MEDLINE (PubMed), Excerpta Medica Database, Cumulative Index to Nursing and Allied Health Literature, and International Organization for Standardization. Electronic databases were searched using keywords related to terminology of audiology: 'terminology of audiology,' 'terminology of hearing loss,' 'terminology of hearing impaired,' and 'terminology of communication sciences and disorders.' The studies were initially identified according to the titles of 2921 publications following careful abstract examination. Of these, whole texts of 16 publications were retrieved. Five papers met the inclusion criteria described below and were further investigated (Table 1). In phase 2, a manual search was conducted to collect additional publications with keywords related to terminology project in audiology. A total of 16 papers were found

Table 1. Process of sample collection

\begin{tabular}{ll}
\hline & \multicolumn{1}{c}{ Number of data } \\
\hline $\begin{array}{l}\text { Phase 1: } \\
\begin{array}{l}\text { a systematic } \\
\text { review }\end{array}\end{array}$ & $\begin{array}{c}\text { PubMed, EMBASE, CINAHL, ISO, } \mathrm{n}=2921 \\
\text { examination, } \mathrm{n}=16\end{array}$ \\
& $\begin{array}{c}\text { Citations included based on complete text } \\
\text { examination, } \mathrm{n}=5\end{array}$ \\
$\begin{array}{ll}\text { Phase 2: } \\
\text { manual search }\end{array}$ & $\begin{array}{l}\text { Manual search with extended keywords, } \mathrm{n}=11 \\
\text { Total citations }\end{array}$ \\
\hline
\end{tabular}

EMBASE: Excerpta Medica Database, CINAHL: Cumulative Index to Nursing and Allied Health Literature, ISO: International Organization for Standardization
(Table 1).

To investigate potential terminology issues in audiology, relaxed inclusion criteria were applied. English-language publications including peer-reviewed journals, editorials, routine publication, resources, guidelines, or standards published between 1980 and 2015 were considered, as was terminology in audiology or CSD as a major study topic or subject. Qualitative analysis was performed to identify demographics, characteristics, and topics of the publications.

\section{Results}

Table 2 displays a summary of the publications including overall study topics and essential terminology issues in audiology. Twelve studies were review or discussion type publications and the other four included grounded theory, chart review and cross-sectional studies. Among the 16 studies representing terminology related topics in CSD, six papers directly focused on terminology issues in audiology. This was indicative of the paucity of audiology terminology research. Keywords of the publication also confirmed these five main issues of terminology in audiology (Table 3). Specific audiology terms and definitions discussed for improved practices were 'auditory processing disorders [15], 'hearing disorders [16], 'hearing loss [10],' 'nonorganic hearing loss [17],' and 'sensorineural hearing loss $[12,13]$.' In addition, three studies [18-20] suggested the possible emergence of International Classification of Functioning, Disability and Health (ICF) as a conceptual model of terminology in CSD.

\section{Discussion}

This short report investigated the main issues and topics related to terminology of audiology. The study topics of terminology in audiology comprised terms and definitions, terminology model/framework, and challenging terminology issues. Five main terminology issues in audiology categorized were appropriateness, classification/framework, inconsistency of terminology, multilingual/international aspects, and service quality/delivery including communication and accessibility issues.

The IGOTF-CSD [8,9] project launched terminology project in CSD to improve the appropriateness, accessibility, and consistency of terminology. In a practical way, the EuroTermBank project [24] established extensive multilingual terminology networks including audiology category and emphasized the terminology management goals with "high quality of general terms, harmonization, exchangeability, and availability". These projects addressed recurring terminology is- 
Oh SH, et al.

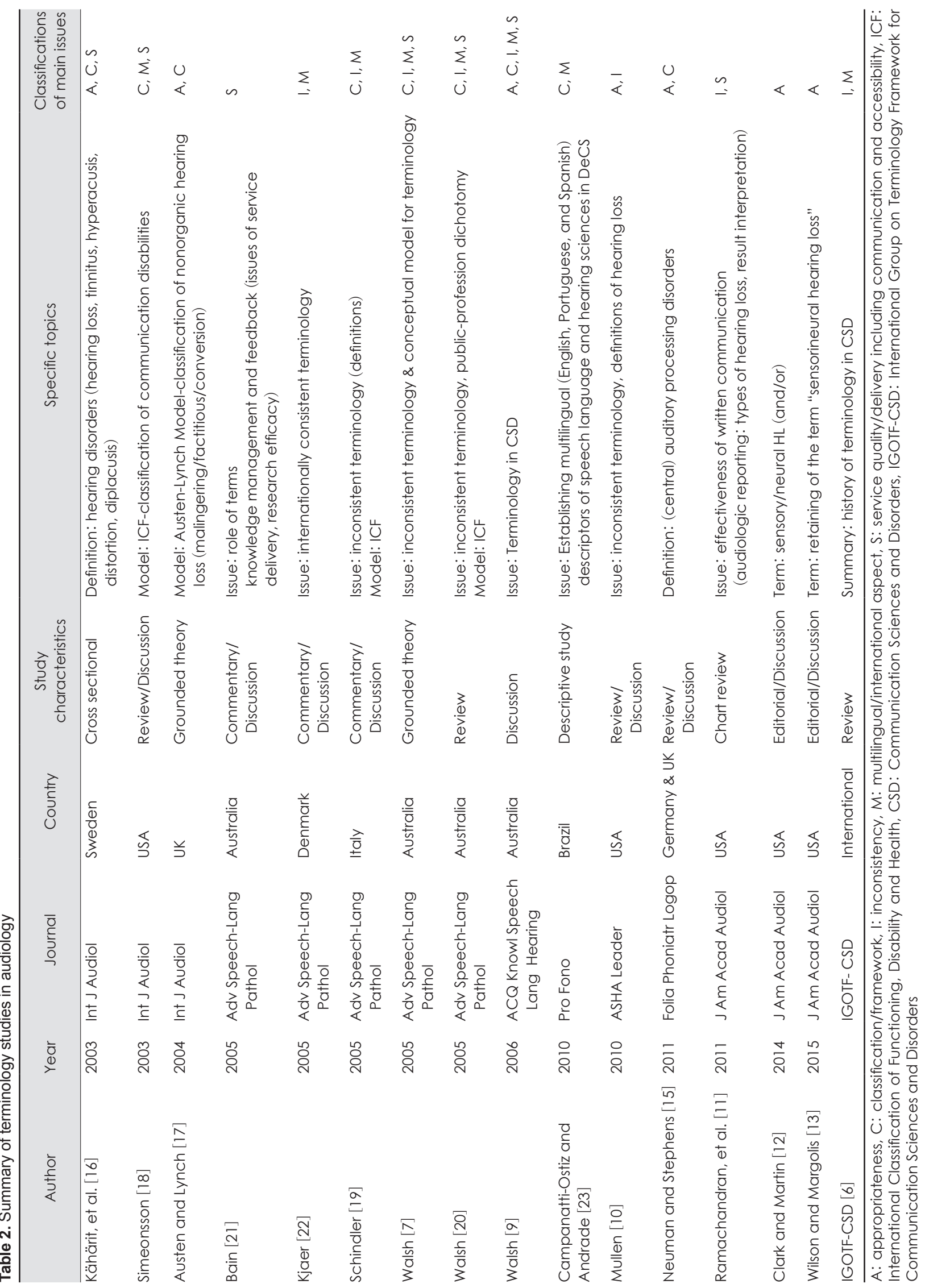


Table 3. Summary of keywords related to terminology issues

\begin{tabular}{cl}
\hline $\begin{array}{c}\text { Classifications of } \\
\text { main issues }\end{array}$ & \multicolumn{1}{c}{ Keywords related to terminology issues } \\
\hline A & Hearing in musicians, hearing disorders, hearing loss, tinnitus, hyperacusis, distortion, diplacusis [16] \\
C & Classification [18] \\
A & Non-organic hearing loss, malingering, factitious hearing loss, functional hearing loss, conversion deafness [17] \\
I & Consistency, conceptual model, framework, communication [20] \\
I, S & Consistency, professional practice, professional profile [9] \\
C & Terminology as topic, subject headings, periodicals, vocabulary, controlled [23] \\
A & Auditory neuropathy, central auditory disorders, hearing impairment [15] \\
S & Audiogram, communication, observer variation [11] \\
\hline
\end{tabular}

A: appropriateness, C: classification/framework, I: inconsistency, M: multilingual/International aspect, S: service quality/delivery including communication and accessibility

sues including inconsistency and accessibility and five main issues in present study showed somewhat similar problems. However, compared to the recurring terminology issues in audiology, the present study indicated the lack of studies and standards directly related to terminology in audiology, and the lack of professional awareness and normalized terms in audiology.

A definition-based approach is one way to resolve terminology issues in CSD. One term- and definition-based approach focused on the use or establishment of common standardized terms [6]. The Euro TermBank project [24] addressed the importance of standardized terminology, centering on consistency and appropriateness of terms. It also provided methodological information leading to national and international consolidation to resolve terminology issues and establish standardized terms. Developing common standardized terms may depend on clarification, consensus, and harmonization of existing terms [24] and underlies best practice and effective communication for both professional and public sectors. In other words, establishing appropriate terms with high quality and consensus supports the use of unambiguous and consistent terms and definitions, thereby improving diagnostic evaluation and minimizing communication difficulties.

On the other hand, the model or framework based approach is suggested to improve terminology issues [6]. This approach provides systematic and conceptual structures of terminology and considers various possible uses, relations, and interactions among relevant stakeholders to improve overall underlying issues in terminology. Walsh's model [20] advocating the IGOTF-CSD project emphasized two primary stakeholder distinctions between profession-specific terminology and public terminology. Profession-specific terminology considers diagnostic purposes, descriptive purposes, research purposes, tentative clinical labels, and discredited labels. Public terminology focuses on service delivery purposes, lobbying and advocacy purposes, and political and legisla- tive purposes. A biopsychosocial model of ICF was suggested as a universal framework to establish consistent terms for appropriate assessments and documentations. It also considers multiple communication difficulties and international and multicultural challenges [18-20].

The collective data indicate that the use of consistent terminology is an underlying factor to improve terminology issues in audiology. Furthermore, improving service quality and delivery depends on the use of consistent terms, effective communication, easy accessibility, and positive impacts on ongoing interactions of multiple stakeholders including professionals, clinicians, patients, and administrators. For these reasons, achieving national and international consensus and harmonization will help resolve various terminology issues in audiology. In other words, establishment of standardized terminology in audiology may minimize current challenging terminology issues by improving appropriateness and consistency of terminology as well as communication among relevant stakeholders at national and international levels.

\section{Acknowledgments}

This work was supported by a grant from the Korean Ministry of Trade, Industry \& Energy, Project No. 10053685.

\section{Conflicts of interest}

The authors have no financial conflicts of interest.

\section{REFERENCES}

1) American Speech-Language Hearing Association. Hearing and balance. Available from: http://www.asha.org/public/hearing/.

2) Academy of doctors of audiology. Scope of practice. Available from: http://www.audiologist.org/scope-of-practice.

3) American Speech-Language Hearing Association. Market trends in audiology and speech-language pathology. Available from: http:// www.asha.org/Careers/Market-Trends/.

4) ISO 10241-1. Terminological entries in standards-Part 1: General requirements and examples of presentation. Geneva: ISO;2011.

5) ISO 10241-2. Terminological entries in standards-Part 2: Adoption of standardized terminological entries. Geneva: ISO;2012.

6) International Group on Terminology Framework-Communication Sci- 
ence and Disorders. A history of the terminology of communication sciences and disorders (IGOTF-CSD). Available from: http://www. speechpathologyaustralia.org.au/library/A\%20History\%20of\%20 Communication\%20Sciences\%20and\%20Disorders.pdf.

7) Walsh R. Meaning and purpose: a conceptual model for speech pathology ternology. Adv Speech-Lang Pathol 2005;7:65-76.

8) International group on terminology framework-Communication science and disorders 2006. Terminology frameworks project profile. Available from: http://www.speechpathologyaustralia.org.au/ library/Draft\%20Plan\%20IGOTF\%20June06.pdf.

9) Walsh R. Terminology-much more than a definition. ACQ Knowl Speech Lang Hearing 2006;8:39-41.

10) Mullen R. Clarifying our terminology: moving the discipline forward by defining terms and sharing data. ASHA Leader 2010;15:16-9.

11) Ramachandran V, Lewis JD, Mosstaghimi-Tehrani M, Stach BA, Yaremchuk KL. Communication outcomes in audiologic reporting. J Am Acad Audiol 2011;22:231-41.

12) Clark JG, Martin FN. Time for a change: a note on hearing loss terminology. J Am Acad Audiol 2014;25:1034-5.

13) Wilson RH, Margolis RH. Hearing loss terminology should be evidence based: a reply to clark and martin (2014). J Am Acad Audiol 2015;26:524-5.

14) Kim HJ, Lee HJ. Proposal of audiologic terminology standardization in Korea. Korean J Audiol 2009;13:116-27.

15) Neumann K, Stephens D. Definitions of types of hearing impairment: a discussion paper. Folia Phoniatr Logop 2011;63:43-8.
16) Kähärit K, Zachau G, Eklöf M, Sandsjö L, Möller C. Assessment of hearing and hearing disorders in rock/jazz musicians. Int J Audiol 2003;42:279-88.

17) Austen S, Lynch C. Non-organic hearing loss redefined: understanding, categorizing and managing non-organic behaviour. Int J Audiol 2004;43:449-57.

18) Simeonsson RJ. Classification of communication disabilities in children: contribution of the international classification on functioning, disability and health. Int J Audiol 2003;42 Suppl 1:S2-8.

19) Schindler A. Terminology in speech pathology: old problem, new solutions. Adv Speech-Lang Pathol 2005;7:84-6.

20) Walsh R. A response to eight views on terminology: is it possible to tame the wild beast of inconsistency. Adv Speech-Lang Pathol 2005; 7:105-11.

21) Bain A. A systems view of terminology. Adv Speech-Lang Pathol 2005;7:94-7.

22) Kjaer BE. Terminology and conception of the profession. Adv Speech-Lang Pathol 2005;7:98-100.

23) Campanatti-Ostiz H, Andrade CR. Health sciences descriptors in the brazilian speech-language and hearing science. Pro Fono 2010;22: 397-402.

24) Rirdance S, Vasiljevs A. Towards consolidation of European terminology resources: Experience and recommendations from Euro TermBank project. Riga, Latvia; 2006. Available from: http://www. eurotermbank.com/download/EuroTermBank_Towards_Consolidation_of_European_Terminology_Resources.pdf. 